\title{
Protocolo de adquisición de imágenes diagnósticas por termografía infrarroja
}

\author{
Acquisition protocol of diagnostic imaging by infrared thermography
}

\author{
Lina M. Ramírez-Arbeláez MSc', Kelly T. Jiménez-Díaz Ing. BioMD², \\ Andrés C. Correa-Castañeda Ing. BioMD², Julián A. Giraldo-Restrepo Ing. BioMD²,
}

Hermes A. Fandiño-Toro $\mathrm{MSc}^{3}$

Introducción: en aplicaciones biomédicas, la termografia infrarroja ha permitido visualizar el patrón de distribución de temperatura de la piel y el tejido subyacente, permitiendo diagnosticar problemas vasculares o nerviosos y, particularmente, trastornos en la termorregulación como el fenómeno de Raynaud y la intolerancia al frío. Sin embargo, las publicaciones no detallan el protocolo de adquisición de imágenes ni validan el mismo; factores determinantes para la calidad y relevancia de la información diagnóstica obtenida. Objetivo: diseñar y validar un protocolo de adquisición de imágenes por termografia infrarroja para analizar la termorregulación en la mano. Materiales y métodos: Se diseñó un nuevo protocolo de adquisición de imágenes por termografía infrarroja utilizando un estímulo frío en la mano. Se analizaron estadísticamente regiones de interés de imágenes termográficas de 18 mediciones intrasujeto en un único sujeto y mediciones intersujeto en 17 individuos sanos. Resultados: En las mediciones intrasujeto e intersujeto se encontró que 10 minutos después del estímulo frío el porcentaje de recuperación de la temperatura fue cercano al 100\%, excepto en un individuo en el cual, a pesar de no reportar enfermedades o lesiones previas, la punta de los dedos después del estímulo alcanzó apenas los $28^{\circ} \mathrm{C}$. La prueba de fatiga en uno de los sujetos sanos mostró alteraciones en el proceso de termorregulación de la mano cuando el protocolo se repite en corto tiempo. Conclusiones: luego del cumplimiento de las especificaciones propuestas se obtuvo un protocolo reproducible y confiable para el análisis del proceso de termorregulación de la mano.

Palabras clave: protocolo de adquisición, termografia infrarroja, diagnóstico por imágenes, termorregulación.

Introduction: In biomedical applications, infrared thermography has allowed to visualize the temperature distribution patterns of skin and underlying tissue, allowing the diagnosis of vascular or nervous disorders, particularly disturbances in the thermoregulation process as Raynaud's phenomenon and cold intolerance. However, most papers not detailed the images acquisition protocol or its validation,

\footnotetext{
'Ingeniera Biomédica, MSc en Física Médica. Docente, Departamento de Ciencias Aplicadas, Instituto Tecnológico Metropolitano. Medellín, Colombia Correspondencia: calle 73 \# 76A-354. Correo electrónico: linaramirez@itm.edu.co

${ }^{2}$ Estudiante de Ingeniería Biomédica, Departamento de Ciencias Aplicadas, Instituto Tecnológico Metropolitano. Medellin, Colombia

3Ingeniero Electrónico, MSc en Ingeniería-Automatización Industrial. Docente, Departamento de Sistemas, Instituto Tecnológico Metropolitano. Medellín, Colombia

Conflicto de intereses: los autores declaran que no tienen conflicto de intereses Medicina \& Laboratorio 2015; 21: 161-178

Módulo 19 (Investigación), número 32. Editora Médica Colombiana S.A. $2015^{\odot}$

Recibido el 30 de marzo de 2015; aceptado el 26 de abril de 2015
} 
being these two determining factors to the quality and relevance of the obtained diagnostic information. Objective: To design and validate an acquisition protocol of diagnostic imaging by infrared thermography to analyze the thermoregulation process in hand. Material and methods: It was designed a new acquisition protocol of diagnostic imaging by infrared thermography using a cold stimulus in hand. It was statistically analyzed the regions of interest of thermographic images of 18 intrasubject measurements (in one individual) and intersubject measurements in 17 healthy individuals. Results: In the intrasubject and intersubject measurements, it found that 10 minutes after the cold stimulus the temperature measured was close to 100\% of initial temperature, except for one of healthy subjects who, despite not report diseases or previous injuries, the temperature of the fingertips after stimulus barely reached $28{ }^{\circ} \mathrm{C}$. The fatigue test in one healthy subject presents alterations in the thermoregulation process in hand when the protocol was repeated in a short time. Conclusion: After the implementation of the proposed specifications, it was obtained a reproducible and reliable protocol to analyze the process of thermoregulation on hand.

Keywords: acquisition protocol, infrared thermography, medical diagnostic imaging, thermoregulation.

Ramírez- Arbeláez LM, Jiménez-Díaz KT, Correa-Castañeda AC, Giraldo-Restrepo JA, Fandiño-Toro HA. Protocolo de adquisición de imágenes diagnósticas por termografia infrarroja. Medicina \& Laboratorio 2015; $21: 161-178$.

L a termografía infrarroja hace referencia a la cuantificación de la energía radiante que emite todo objeto cuya temperatura esté por encima del cero absoluto, pero que es invisible para los humanos pues involucra longitudes de onda correspondientes al espectro electromagnético infrarrojo [I]. Mediante el uso de arreglos bidimensionales de sensores sensibles a dicha energía se obtienen los denominados termogramas, que son representaciones de la distribución espacial de las temperaturas de la superficie analizada con una cámara de termografía infrarroja [2]. Dado que el uso de la termografía infrarroja no supone de ninguna manera la emisión de ningún tipo de radiación sobre las superficies analizadas, se considera que es una técnica segura, no invasiva (no requiere del contacto físico entre los sensores y las superficies analizadas), no dolorosa y de bajo costo (comparada con otras técnicas de imaginología diagnóstica), que permite el registro de la energía radiante infrarroja que emite el cuerpo humano de forma natural [3]. Estas características hacen a la termografía infrarroja particularmente útil, siempre que se valide su uso, para el potencial diagnóstico de condiciones patológicas que impliquen la presencia de manifestaciones de tipo térmico que puedan registrarse mediante imágenes de termografía infrarroja, como aquellas que alteran el proceso de termorregulación.

En aplicaciones biomédicas la termografía infrarroja permite la visualización de patrones de distribución de temperatura de la piel y, en algunos casos, de tejido subyacente en el cuerpo humano. Tanto los patrones de distribución como los valores reales de temperatura se utilizan como indicadores para el diagnóstico potencial de condiciones patológicas relacionadas con la fisiología del sistema vascular y del sistema nervioso periférico [4]. De forma general, los principios que soportan la implementación del análisis basado en termografía infrarroja en aplicaciones biomédicas consideran las variaciones en el flujo sanguíneo de las superficies de la piel analizadas que pueden afectar la temperatura de la piel [5]. De esta manera, se ha utilizado la termografía infrarroja para el análisis no invasivo de enfermedades vasculares, estados febriles, 
cáncer de mama, temperatura de la superficie ocular [6], así como el análisis de la artritis inflamatoria, la osteoartritis, el reumatismo de tejidos blandos, el síndrome del túnel carpiano y el síndrome de dolor regional complejo [7].

Los denominados fenómeno de Raynaud e intolerancia al frío pueden presentarse como consecuencia de lesiones en los nervios periféricos o como secuelas de una enfermedad de base. Estas condiciones se caracterizan por producir, en los individuos que las padecen, un dolor anormal en la extremidad afectada cuando se expone a climas, ambientes o sustancias frías [8- I0]. Además, ambos pueden producir alteraciones en la irrigación de la extremidad comprometida en respuesta al estímulo frío, que se pueden registrar mediante termografía infrarroja $[\mathrm{I}, \mathrm{I} \mathrm{I}]$. Lo anterior corresponde al efecto contrario a lo que ocurre en personas sanas, en las cuales el sistema nervioso periférico responde a un estímulo frío produciendo vasodilatación o vasoconstricción de los vasos sanguíneos en un esfuerzo por contrarrestar cualquier posible baja de temperatura del tejido inferior a los límites fisiológicos por efecto del estímulo [I I ].

El fenómeno de Raynaud puede afectar entre un 3\% y 5\% de la población y la intolerancia al frío se estima que la padecen entre el $56 \%$ y $70 \%$ de pacientes que sufrieron algún tipo de lesión en los nervios periféricos de una extremidad $[12,13]$. Estas condiciones tienen en común que se diagnostican mediante la evaluación clínica, en la cual se determina la presencia y extensión de la enfermedad [9,|4-16]. No obstante, no se cuenta con una técnica diagnóstica objetiva que permita correlacionar los síntomas con la fisiología del paciente ni se realiza una prueba diagnóstica de soporte por parte del personal médico que permita validar los signos o síntomas que presenta el paciente.

En lo que se refiere al análisis de termografía infrarroja realizado en personas resultan útiles los hechos de que: a) El cuerpo humano se comporta de forma similar a un cuerpo negro, pues la superficie de la piel irradia energía térmica que de forma general no se ve afectada por la reflexión ni por la transmisión de energía térmica radiada por objetos cercanos y b) Lo primero que se necesita para adquirir una imagen de termografía infrarroja es que exista un contraste térmico entre la superficie que se planea analizar y los objetos circundantes a dicha superficie, contraste térmico que es fácilmente obtenible en el caso de la superficie del cuerpo humano al utilizar un fondo para las imágenes cuya temperatura difiera de la temperatura corporal, lo cual suele ser logrado fácilmente [17,18]. No obstante, la adquisición de imágenes de termografía infrarroja demanda la consideración y especificación de variables que pueden producir errores en las mediciones de temperatura obtenidas, siendo las más relevantes las de tipo ambiental, de tipo óptico para la cámara utilizada y otras referidas al posicionamiento de la cámara y a la preparación del sujeto cuya superficie corporal se va a visualizar [19-2|]. Dada la evidencia existente de que las imágenes de termografía infrarroja pueden ser valiosas para evaluar el fenómeno de Raynaud y la intolerancia al frío [3,7, I2- | 4], se han publicado trabajos en los que se describen protocolos con diferentes tiempos de estimulación fría, que varían entre uno y cinco minutos [6,8,9] [ I4,2। ], diferentes tiempos de medición de temperatura después del estímulo, que oscilan entre 12, 20 y 30 minutos, e incluso casos en que se espera la recuperación total de la temperatura basal en la mano [6,8,2।,22].

En este trabajo se presenta el diseño y la validación de un protocolo para la adquisición de secuencias de imágenes de termografía infrarroja para analizar el proceso de termorregulación de la mano. Para dicho protocolo se define una serie de etapas donde se especifican 
parámetros de importancia relacionados con la cámara de termografía infrarroja utilizada, se especifican las condiciones bajo las cuales se hacen las adquisiciones de imágenes en los sujetos de prueba y se analiza estadísticamente la variabilidad de las mediciones de temperatura obtenidas tras la aplicación del protocolo. Finalmente, se presenta una discusión, junto con algunas conclusiones, sobre la validez del protocolo de termografía infrarroja como potencial herramienta diagnóstica.

\section{Materiales y métodos}

\section{Protocolo de adquisición}

La adquisición de las imágenes se realizó con una cámara termográfica FLIR A655sc (FLIR Systems, Oregón, Estados Unidos), la cual tiene una resolución de 640 × 480 píxeles y una exactitud $\pm 2{ }^{\circ} \mathrm{C} \circ 2 \%$ de la lectura. En las imágenes adquiridas cada píxel corresponde a un valor de temperatura local del área que se está capturando con la cámara. El archivo que se obtiene para cada grabación es una secuencia de imágenes termográficas y, a partir de cada secuencia, se construyen cinco curvas que muestran la evolución de la temperatura promedio de una región representativa de cada uno de los dedos de la mano durante el tiempo que dura la prueba. Las condiciones ambientales se supervisaron continuamente, realizando mediciones de temperatura ambiente y humedad relativa durante las pruebas. La emisividad de la piel se fijó en 0,98, según lo descrito en la literatura [8], y el valor mínimo y máximo de temperatura registrable con la cámara fueron asignados a $25^{\circ} \mathrm{C}$ y $38^{\circ} \mathrm{C}$, respectivamente. Los valores de temperatura ambiente y humedad relativa fueron determinados mediante el uso de un termohigrómetro Extech (Extech Instruments, Nashua, Nuevo Hampshire, Estados Unidos) antes de cada adquisición. Los valores de estos dos parámetros junto con el valor de la emisividad se especificaron en el software que controla la cámara. Los valores de temperatura que ofrece la cámara dependen de la correcta especificación de los parámetros de temperatura ambiente, humedad relativa y emisividad.

La cámara termográfica se posicionó de forma vertical en un trípode a $58 \mathrm{~cm}$ de la mano (véase figura I). Antes de realizar cada adquisición el sujeto permaneció en reposo durante 15 minutos en posición sentada en una camilla, sin tocar ninguna superficie 0 equipo que pudiese alterar la temperatura basal de la extremidad analizada.

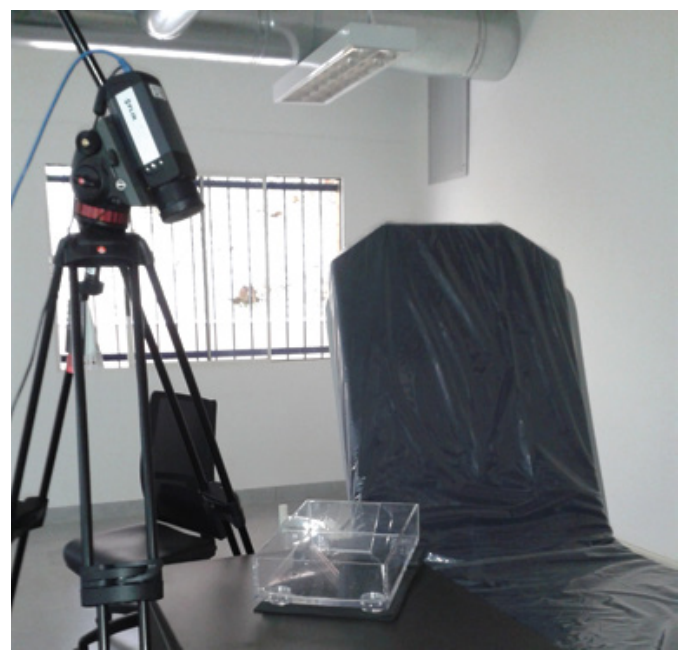

Figura I. Sistema de medición: cámara termográfica, camilla y soporte de acrílico.

Para iniciar la adquisición se posicionó al sujeto en la silla con el codo flexionado aproximadamente a $90^{\circ}$ sobre la mesa y la mano fija sobre un soporte de acrílico. La palma de la mano se ubicó en el fondo del soporte y la muñeca en la rampa de $31^{\circ}$ para permitir un mejor apoyo y 
mayor comodidad del sujeto. El soporte de acrílico fue diseñado en el Laboratorio de Ingeniería Biomédica (campus Fraternidad) del Instituto Tecnológico Metropolitano (ITM), Medellín, Colombia (véase figura 2), cuyas principales funciones eran: a) Permitir el estímulo con agua fría minimizando la posibilidad de movimiento de la mano y b) Disminuir la influencia de luz ambiente que pudiera reflejarse en el sistema de medición.
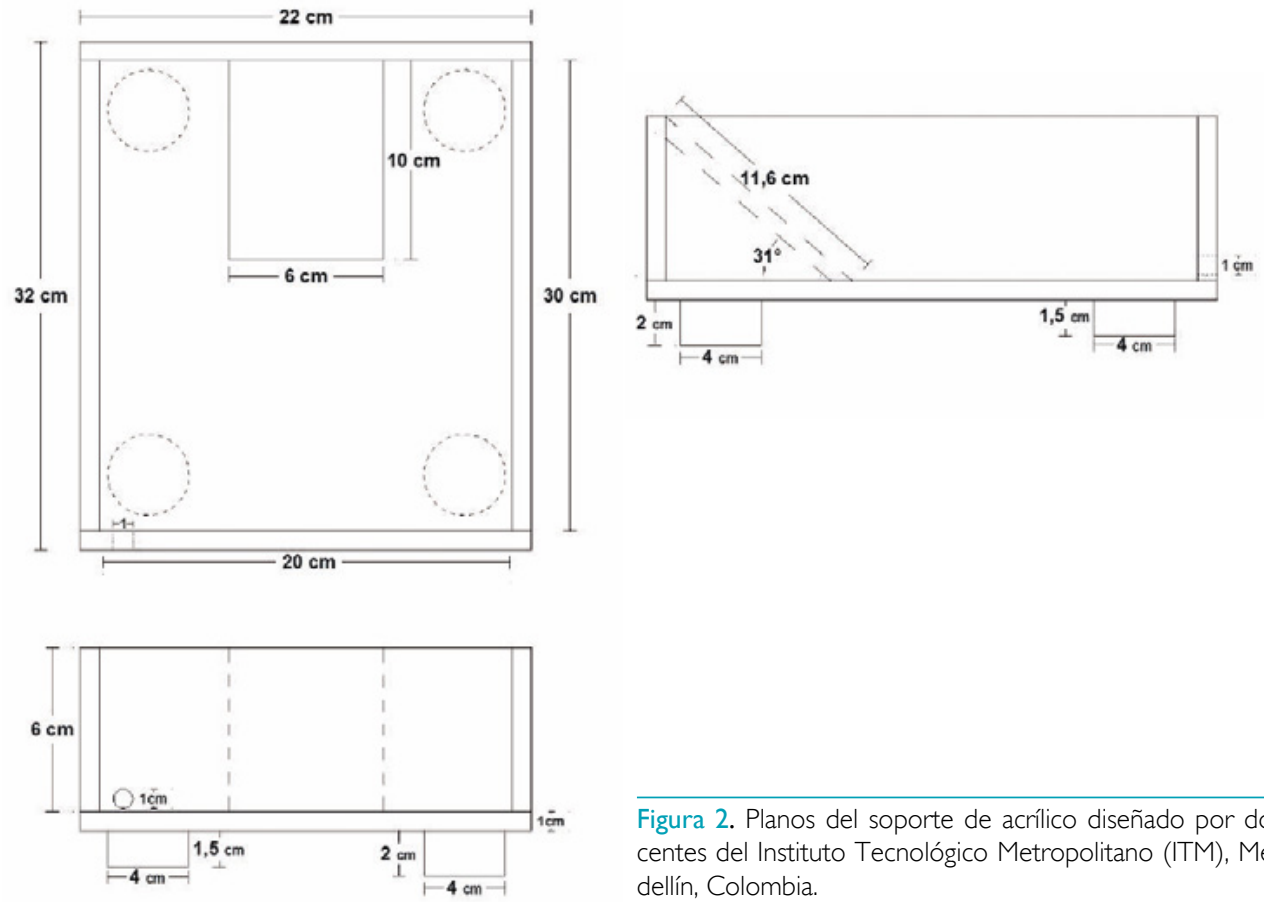

Figura 2. Planos del soporte de acrílico diseñado por docentes del Instituto Tecnológico Metropolitano (ITM), Medellín, Colombia.

Se definió una distancia de $58 \mathrm{~cm}$ entre la cámara y el soporte de acrílico para obtener un campo de visión (FOV; del inglés Field Of View) de 25,4 ×19,2cm², cálculo que se realizó según los parámetros de la cámara reportados por el fabricante y la fórmula matemática descrita previamente en la literatura [2 l]. La mano se posicionó centrada en el campo de visión, incluyendo toda la muñeca hasta la apófisis estiloides del cúbito.

Teniendo en cuenta que el protocolo propuesto está orientado hacia el diagnóstico de pacientes con intolerancia al frío y fenómeno de Raynaud, y que estos deben soportar la prueba sin mover la mano, se realizó una prueba piloto en sujetos sanos con estímulos de 15, 30 y 60 segundos, en la que se sumergía la mano en agua fría a $15^{\circ} \mathrm{C}$, y se midió la respuesta al estímulo y el tiempo que tardaba la mano en recuperar nuevamente su temperatura basal. Así se definió que con un tiempo de estímulo de 30 segundos y un tiempo de medición de la temperatura posterior al estímulo de 10 minutos se obtenía información suficiente para evaluar el proceso de termorregulación de la mano y se podía evaluar la reaclimatación en un porcentaje cercano al $100 \%$ de la temperatura inicial.

En resumen, el protocolo de adquisición de imágenes termográficas se definió tal y como lo indica la figura 3. Antes del estímulo se realizó una medición de la temperatura basal de la mano durante dos minutos para garantizar la estabilidad de la temperatura al iniciar la prue- 
ba. El estímulo frío se realizó con agua a $15^{\circ} \mathrm{C}$ durante 30 segundos; para esto, se llenó el soporte de acrílico hasta cubrir el dorso de la mano en su totalidad. Durante este proceso la mano permaneció horizontal, sin moverse de su posición inicial. Concluido el estímulo, se drenó el recipiente y se adquirieron imágenes durante 10 minutos adicionales. El tiempo total de medición, teniendo en cuenta las anteriores etapas, fue de aproximadamente 13,5 minutos.

\section{Mediciones intrasujeto}

Para verificar la variabilidad de los resultados, siguiendo el protocolo diseñado cuando las condiciones de medición propias del sujeto no se modifican, se realizaron 18 mediciones en un único sujeto sano. El número de mediciones se definió según el tiempo y los recursos

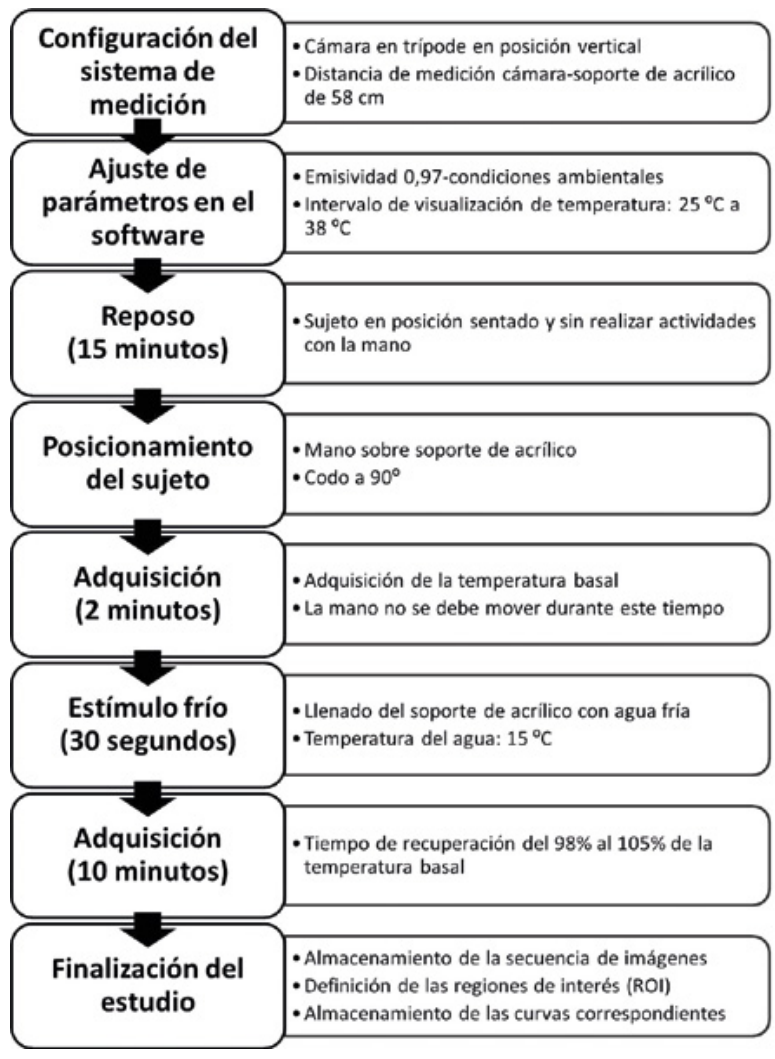

Figura 3. Diagrama de flujo del protocolo de adquisición de imágenes por termografía infrarroja. disponibles en el laboratorio. Para esto, se calculó el porcentaje de reaclimatación en cada secuencia de mediciones para cada uno de los dedos del sujeto. Se realizó una prueba adicional de mediciones consecutivas para medir la fatiga de la mano al repetir la prueba; en esta prueba se hicieron cinco mediciones siguiendo el protocolo diseñado sin dejar tiempo de espera adicional entre las mediciones más que el tiempo de reposo inicial contemplado en el protocolo.

\section{Mediciones intersujeto}

Se realizaron mediciones en 17 sujetos sanos seleccionados mediante muestreo por conveniencia y teniendo en cuenta el tiempo y los recursos disponibles en el laboratorio. Para cada uno de los sujetos se calculó el porcentaje de reaclimatación 10 minutos después del estímulo frío en cada uno de los dedos.

\section{Regiones de interés}

Se definieron cinco regiones de interés (ROl; del inglés, Region Of Interest) con ayuda del software FLIR ResearchIR provisto en la cámara termográfica. Cada región de interés se ubicó en la falange distal de cada uno de los dedos de la mano derecha del sujeto sin tocar la uña, debido a que se conoce que la uña tiene una emisividad diferente a la de la piel [23] y, por tanto, no suele considerase en los estudios que involucran el análisis termográfico de la región corres- 
pondiente a la mano [24]. Antes de obtener la curva con la evolución de la temperatura para cada región de interés se verificó que, durante las adquisiciones, la mano no registrara movimientos que pudiesen generar cambios de posición de las regiones de interés, que introdujeran errores en los cálculos de temperatura. La curva de temperatura de cada dedo se determinó mediante el cálculo de la temperatura promedio de los valores de temperatura de los píxeles de las regiones de interés correspondientes en cada imagen de la secuencia. Esta información se representó como curvas de temperatura en relación al tiempo.

\section{Análisis estadístico}

Para las 18 mediciones del mismo sujeto y en las mediciones de los 16 sujetos sanos se calcularon los porcentajes de recuperación de la temperatura 10 minutos después del estímulo. Los valores correspondientes a cada dedo se analizaron con la prueba de KolmogorovSmirnov, la cual permite verificar si un conjunto de datos sigue una distribución normal y es aplicable a muestras pequeñas [25]. Dado que la prueba de Kolmogorov-Smirnov mostró que en todos los casos los datos seguían una distribución normal, se aplicó la prueba F, que analiza la igualdad de las varianzas y determina si se debe aplicar la t-student para varianzas iguales o desiguales según el caso y para muestras independientes, y la prueba de hipótesis de t-student, una prueba paramétrica para comparar las medias de dos muestras, que presenta una selección de los datos de forma aleatoria [26]. Un valor de $p$ menor que 0,05 fue considerado como significativo.

Las pruebas se realizaron utilizando el software matemático $R$ ( $R$ Development Core Team (20।3), R Foundation for Statistical Computing, Viena, Austria), con el objetivo de verificar que los datos correspondieran a la misma población, es decir, al grupo de sujetos sanos. Las pruebas se aplicaron separando cada grupo de datos (correspondientes a cada dedo) en dos muestras y comparándolas entre sí. La construcción de las muestras se hizo de forma aleatoria y se realizó por triplicado para garantizar que la aleatorización de las muestras no influyera en el resultado, el procedimiento de obtener las muestras y la aplicación del análisis estadístico.

Las curvas de temperatura, en relación con el tiempo, se construyeron incluyendo la curva media y las bandas de confianza de dos desviaciones estándar, correspondientes a los límites superior e inferior de los intervalos de confianza del $95 \%$.

\section{Resultados}

\section{Sujetos sanos del estudio}

En la tabla | se presenta la caracterización de los 17 sujetos sanos seleccionados para las mediciones. Ninguno de ellos presentaba antecedentes de enfermedad vascular o nerviosa en las extremidades superiores, ni lesiones previas en la mano. Uno de los sujetos fue excluido de las mediciones in-

\begin{tabular}{|c|c|c|c|}
\hline Género & Número & $\begin{array}{l}\text { Edad promedio } \\
\text { (años) }\end{array}$ & $\begin{array}{l}\text { Rango de } \\
\text { edad (años) }\end{array}$ \\
\hline \multicolumn{4}{|c|}{ Mediciones intersujeto } \\
\hline Masculino & 9 & 25 & 19 a 34 \\
\hline Femenino & 7 & 25 & 18 a 35 \\
\hline \multicolumn{4}{|c|}{ Mediciones intersujeto descartadas } \\
\hline Masculino & 1 & 20 & - \\
\hline \multicolumn{4}{|c|}{ Mediciones intrasujeto } \\
\hline Masculino & I & 23 & - \\
\hline
\end{tabular}


tersujeto debido a que no recuperó la temperatura de la mano. De los 16 sujetos incluidos para estas mediciones, siete eran de sexo femenino y nueve de sexo masculino, ambos grupos con una edad promedio de 25 años. Un solo sujeto de sexo masculino, 23 años de edad y sin antecedentes de enfermedad vascular o nerviosa en las extremidades superiores ni lesiones previas en la mano fue seleccionado para las mediciones intrasujeto.

\section{Secuencia de imágenes de termorregulación de sujetos sanos durante el protocolo diagnóstico a diferentes tiempos}

En general, en la secuencia de imágenes de termorregulación se pudo observar el efecto del estímulo frío en la mano y cómo responde el sistema termorregulador (véase figura 4). Antes del estímulo se pudo observar cómo las temperaturas están distribuidas en la mano con un patrón definido, particularmente en los dedos (véase figura 4A). Un minuto después del estímulo todavía la temperatura de la mano se conservaba, en buena parte, por debajo de los $25^{\circ} \mathrm{C}$. En este tiempo se ve sobresalir una vena que se extiende del plexo venoso dorsal y continúa en la vena basílica con temperatura inferior a $25^{\circ} \mathrm{C}$ por la que regresa la sangre proveniente de la zona estimulada (véase figura 4B). Tres minutos después del estímulo se observó que la punta de los dedos es la zona donde más se recupera la temperatura; sin embargo, se observaron zonas donde la temperatura aún continuaba por debajo de los $25^{\circ} \mathrm{C}$ (véase figura $4 \mathrm{C}$ ).

Cinco minutos después del estímulo frío se observó que en la mano se disminuían, paulatinamente, las zonas con temperatura inferior a $25^{\circ} \mathrm{C}$ y que la falange distal de los dedos ya no sobresalía con temperaturas cercanas a los $35^{\circ} \mathrm{C}$ (véase figura 4D). Siete minutos después del estímulo se observó que la mayor parte de la superficie de la mano había recuperado una temperatura superior a los $33^{\circ} \mathrm{C}$ y que las puntas de los dedos habían recuperado la temperatura que tenía la mano antes del estímulo (aproximadamente $35^{\circ} \mathrm{C}$ ) (véase figura 4E). Luego de 10 minutos del estímulo se observó un efecto particular: algunas zonas de la mano, específicamente los dedos y las zonas donde se trazan los vasos sanguíneos, presentaron una temperatura superior a la temperatura anterior al estímulo y, de forma simultánea, otras zonas pequeñas todavía no llegaban a los $33^{\circ} \mathrm{C}$ (véase figura 4F).

Uno de los sujetos sanos del estudio no presentó la recuperación de la temperatura basal después del estímulo frío en la secuencia de imágenes de termorregulación (véase figura 5), pese a que reportó que no tenía ninguna enfermedad vascular o nerviosa, y que no había tenido una lesión previa. No obstante, reportó que jugaba baloncesto con frecuencia. Antes del estímulo se observó en la imagen una diferencia de la temperatura entre la parte central de la mano y la punta de los dedos (véase figura 5A) que no se presenta en las imágenes de los demás sujetos (véase figura 4A). En relación con este hallazgo, en las imágenes después del estímulo frío se evidenció que cinco minutos después del estímulo las puntas de los dedos estuvieron con una temperatura inferior a $25^{\circ} \mathrm{C}$; siete minutos después del estímulo apenas se visualiza el pulgar y sólo el extremo distal de los dedos central, anular y meñique, con el dedo índice aún a una temperatura inferior a $25^{\circ} \mathrm{C}$. Luego de 10 minutos del estímulo no se visualiza el dedo índice, lo que indica que la temperatura de éste no alcanzó los $25^{\circ} \mathrm{C}$, el dedo central, anular y meñique presentan temperaturas entre $25^{\circ} \mathrm{C}$ y $28^{\circ} \mathrm{C}$ en la mitad de su superficie y el dedo pulgar está en su totalidad por encima de los $28^{\circ} \mathrm{C}$, siendo el dedo que mejor recuperó la temperatura. 
A
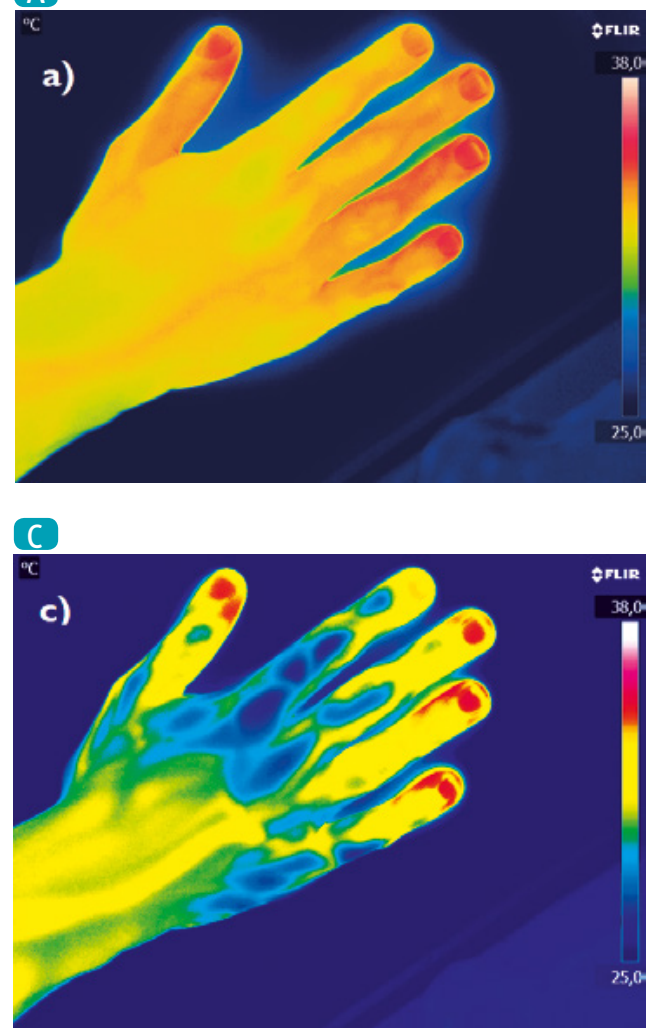

E

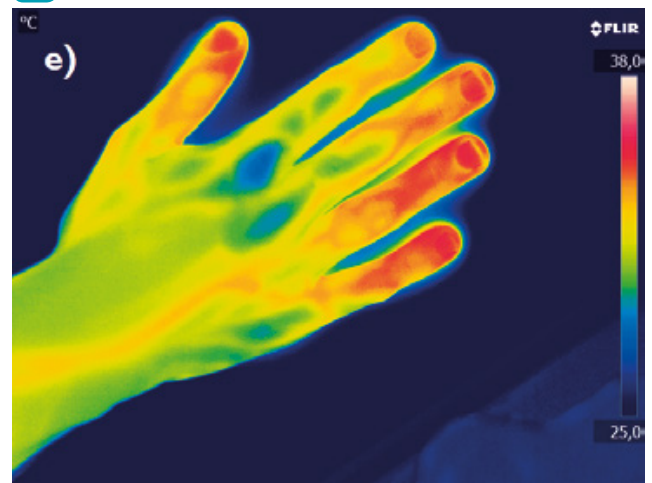

B

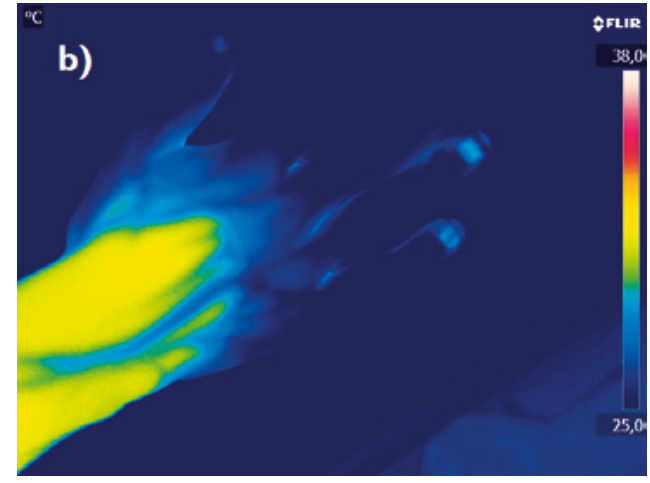

(D)

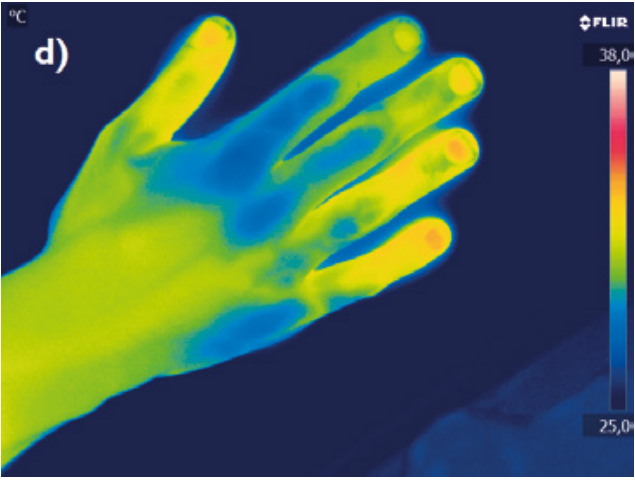

F

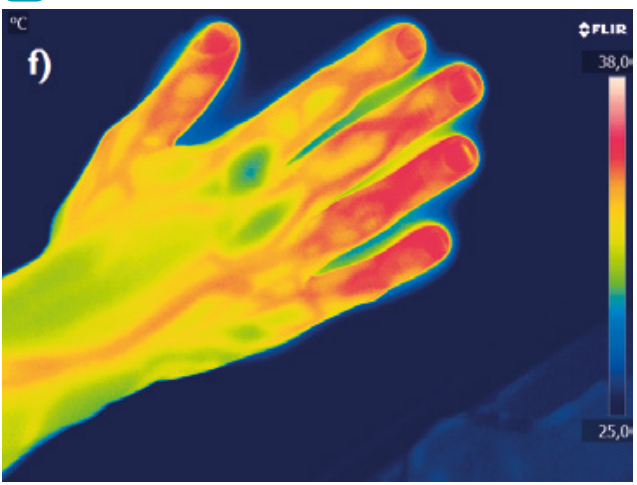

Figura 4. Secuencia de imágenes de termorregulación de un sujeto sano durante el protocolo diagnóstico a diferentes tiempos. A. antes del estímulo, B-F: después del estímulo. B. al minuto, C. a los 3 minutos, D. a los 5 minutos, E. a los 7 minutos y F. a los 10 minutos. Resultado más representativo obtenido en el grupo de sujetos sanos evaluados $(n=17)$.

\section{Mediciones de imágenes de termorregulación: intrasujeto}

La tabla 2 muestra el porcentaje de recuperación de temperatura de las falanges distales de los cinco dedos en las 18 secuencias de mediciones del sujeto sano seleccionado. La prueba de Kolmogorov-Smirnov evidenció la normalidad de los datos. El resultado de la prueba F mostró 
una desigualdad de varianzas para el Dedo I y el Dedo 2 e igualdad de varianzas para el Dedo 3, Dedo 4 y Dedo 5, con un nivel de significancia del 5\%. El resultado de la prueba t-student para varianzas desiguales del Dedo I y Dedo 2, y para varianzas iguales del Dedo 3, Dedo 4 y Dedo 5, dio como resultado la aceptación de la hipótesis nula de igualdad de medias en los cinco casos con un nivel de significancia del $5 \%$.
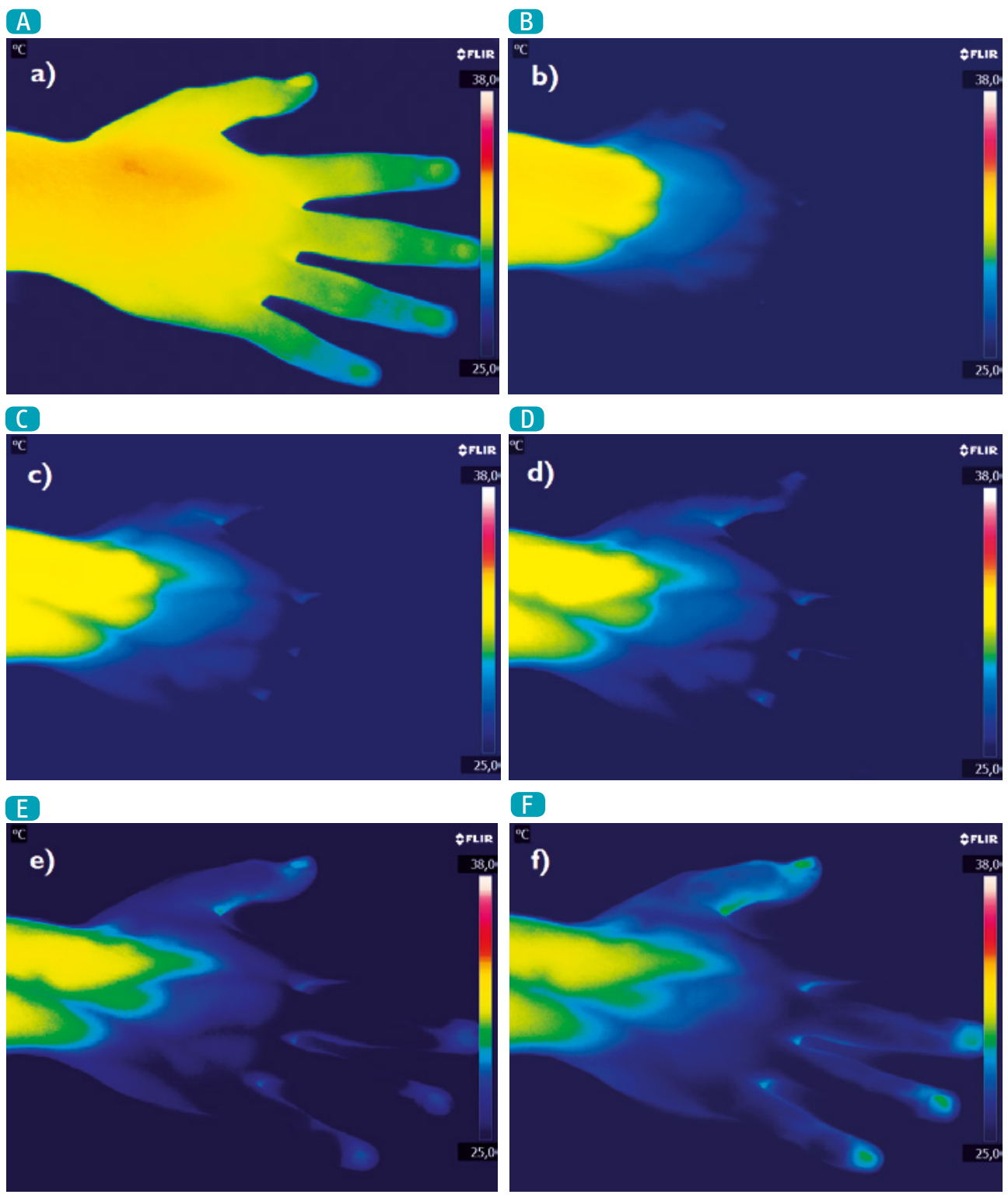

Figura 5. Secuencia de imágenes de termorregulación del único individuo del grupo de sujetos sanos (1/17) que no reaclimató durante el protocolo diagnóstico a diferentes tiempos: A. antes del estímulo, B-F: después del estímulo. B: al minuto, C. a los 3 minutos, D. a los 5 minutos, E. a los 7 minutos y F. a los 10 minutos.

El promedio general de reaclimatación a los 10 minutos del estímulo frío fue del 98,76\%. Algunas mediciones sufrieron un efecto particular, con temperaturas finales superiores hasta en un 5,57\% de la temperatura inicial, siendo 105,57\% el valor más alto de recuperación de temperatura, el 
cual se presentó en el Dedo 5 (meñique). En el Dedo 3 (dedo medio) se registró el valor más bajo de recuperación de temperatura, correspondiente al 94,25\%. Con base en los valores promedio de reaclimatación de todos los dedos, el Dedo I (pulgar) tuvo el menor valor de recuperación de temperatura, con un 98,20\%, y el Dedo 5 (meñique) el mayor valor, con un 99,34\%. El intervalo de reaclimatación de todos los dedos estuvo entre $94,25 \%$ y $105,57 \%$ (véase tabla I).

\begin{tabular}{|c|c|c|c|c|c|c|}
\hline \multirow[t]{2}{*}{ Secuencia } & \multicolumn{6}{|c|}{ Porcentaje de reaclimatación (\%) } \\
\hline & Dedo I & Dedo 2 & Dedo 3 & Dedo 4 & Dedo 5 & Promedio \\
\hline I & 98,08 & 99,10 & 99,54 & 100,33 & 100,62 & 99,53 \\
\hline 2 & 94,55 & 100,53 & 99,41 & 100,37 & 101,22 & 99,22 \\
\hline 3 & 103,12 & 105,19 & 103,13 & 103,97 & 105,57 & 104,20 \\
\hline 4 & 95,58 & 94,70 & 94,25 & 95,35 & 95,96 & 95,17 \\
\hline 5 & 98,83 & 99,03 & 98,71 & 99,33 & 99,16 & 99,01 \\
\hline 6 & 96,53 & 95,38 & 95,34 & 96,41 & 96,37 & 96,01 \\
\hline 7 & 100,07 & 101,26 & 101,32 & 101,67 & 102,05 & 101,27 \\
\hline 8 & 97,46 & 97,76 & 98,25 & 98,43 & 98,78 & 98,14 \\
\hline 9 & 98,49 & 98,39 & 98,39 & 98,39 & 98,65 & 98,46 \\
\hline 10 & 98,44 & 98,55 & 98,63 & 98,52 & 98,90 & 98,61 \\
\hline 11 & 98,46 & 98,14 & 98,19 & 98,56 & 98,65 & 98,40 \\
\hline 12 & 98,41 & 98,23 & 98,32 & 98,51 & 98,54 & 98,40 \\
\hline 13 & 98,36 & 98,37 & 98,56 & 98,61 & 98,80 & 98,54 \\
\hline 14 & 97,83 & 97,80 & 97,87 & 97,90 & 98,46 & 97,97 \\
\hline 15 & 98,06 & 98,21 & 98,26 & 98,37 & 98,66 & 98,31 \\
\hline 16 & 98,76 & 99,19 & 98,94 & 99,17 & 99,50 & 99,11 \\
\hline 17 & 98,66 & 98,75 & 98,77 & 98,89 & 99,19 & 98,85 \\
\hline 18 & 97,93 & 98,52 & 98,63 & 98,40 & 98,96 & 98,49 \\
\hline Promedio & 98,20 & 98,73 & 98,58 & 98,95 & 99,34 & 98,76 \\
\hline
\end{tabular}

\section{Mediciones de imágenes de termorregulación: intersujetos}

En la tabla 3 se presenta el porcentaje de recuperación de temperatura de las falanges distales de los cinco dedos en los 16 sujetos sanos que reaclimataron después de la prueba. La prueba de Kolmogorov-Smirnov evidenció la normalidad de los datos. El resultado de la prueba F fue la igualdad de varianzas para todos los dedos con un nivel de significancia del 5\%. El resultado de la prueba t-student para varianzas iguales en los cinco dedos fue la aceptación de la hipótesis nula de igualdad de medias en los cinco casos con un nivel de significancia del 5\%.

El promedio general de reaclimatación a los 10 minutos del estímulo frío fue del 99,43\%. Algunas mediciones sufrieron un efecto particular, con temperaturas finales superiores hasta en un 2,44\% de la inicial, siendo 102,44\% el valor más alto de recuperación de temperatura, presentado en el Dedo 5 (meñique). En el Dedo I (pulgar) se encontró el valor más bajo de recuperación de temperatura, correspondiente a $96,5 \%$. Considerando el valor promedio de todos los dedos, el Dedo 2 (índice) presentó el menor valor de recuperación de temperatura, 
con un 99,01\%, y el Dedo 5 el mayor valor con un 100,02\%. El intervalo de reaclimatación de todos los dedos estuvo entre $96,5 \%$ y $102,44 \%$ (véase tabla 2).

\begin{tabular}{|c|c|c|c|c|c|c|}
\hline \multirow[t]{2}{*}{ Secuencia } & \multicolumn{6}{|c|}{ Porcentaje de reaclimatación (\%) } \\
\hline & Dedo I & Dedo 2 & Dedo 3 & Dedo 4 & Dedo 5 & Promedio \\
\hline 1 & 99,05 & 98,48 & 97,81 & 97,75 & 99,50 & 98,52 \\
\hline 2 & 101,62 & 100,17 & 100,40 & 101,95 & 100,18 & 100,87 \\
\hline 3 & 98,09 & 99,15 & 99,24 & 98,98 & 100,23 & 99,14 \\
\hline 4 & 98,51 & 99,09 & 99,37 & 99,56 & 102,44 & 99,79 \\
\hline 5 & 100,99 & $|00,3|$ & 100,74 & 100,97 & 98,04 & $|00,2|$ \\
\hline 6 & 98,42 & 97,72 & 98,01 & 98,59 & 98,33 & 98,22 \\
\hline 7 & 98,51 & 98,33 & 99,25 & 99,02 & 99,81 & 98,99 \\
\hline 8 & 97,38 & 97,17 & 98,31 & 98,00 & 99,61 & 98,10 \\
\hline 9 & 101,33 & 100,70 & 100,56 & $|0|, 2 \mid$ & 101,20 & 101,00 \\
\hline 10 & 98,60 & 97,85 & 98,65 & 98,68 & 99,89 & 98,73 \\
\hline 11 & 96,50 & 97,55 & 96,73 & 99,35 & 98,62 & 97,75 \\
\hline 12 & 100,25 & 99,42 & 98,79 & 99,85 & 100,78 & 99,82 \\
\hline 13 & 98,53 & 100,73 & 98,46 & 98,52 & 98,19 & 98,89 \\
\hline 14 & 100,99 & 98,72 & 99,49 & 100,25 & 100,73 & 100,03 \\
\hline 15 & 100,25 & 99,42 & 98,79 & 99,85 & 100,78 & 99,82 \\
\hline 16 & 102,25 & 99,38 & 100,04 & 101,23 & 102,03 & 100,99 \\
\hline Promedio & 99,45 & 99,01 & 99,04 & 99,61 & 100,02 & 99,43 \\
\hline
\end{tabular}

\section{Comparación de las curvas de temperatura con relación al tiempo: mediciones intrasujeto}

La variabilidad de las 18 mediciones intrasujeto se muestra en la figura 6. Como se puede observar entre los 72 y 350 segundos de las curvas se registró la máxima variabilidad, después de este período las curvas se acercan y tienden a estabilizarse. La banda de confianza I corresponde a la curva promedio más dos desviaciones estándar y la banda de confianza 2 corresponde a la curva promedio menos dos desviaciones estándar. Se observó que más del 95\% de las curvas se encuentran dentro de las bandas de confianza lo que indica una baja variabilidad de los datos de un mismo sujeto tomado en momentos diferentes.

\section{Prueba de fatiga}

Los resultados de la prueba de fatiga, es decir, de la influencia de la fatiga en la mano al repetir el estímulo frío de forma consecutiva, realizada en el primer sujeto sano en el marco de las mediciones intrasujeto se presentan en la figura 7. Como se puede observar, a partir de la tercera secuencia de medición la mano no recupera la temperatura inicial a los 10 minutos del estímulo; en la secuencia cinco, después del estímulo, el proceso de reaclimatación es más lento y la temperatura 10 minutos después del estímulo no alcanza los $28^{\circ} \mathrm{C}$, teniendo una diferencia superior a $5{ }^{\circ} \mathrm{C}$ de la primera secuencia de mediciones. 


\section{Comparación Intrasujeto: Curvas de Temperatura vs. Tiempo}

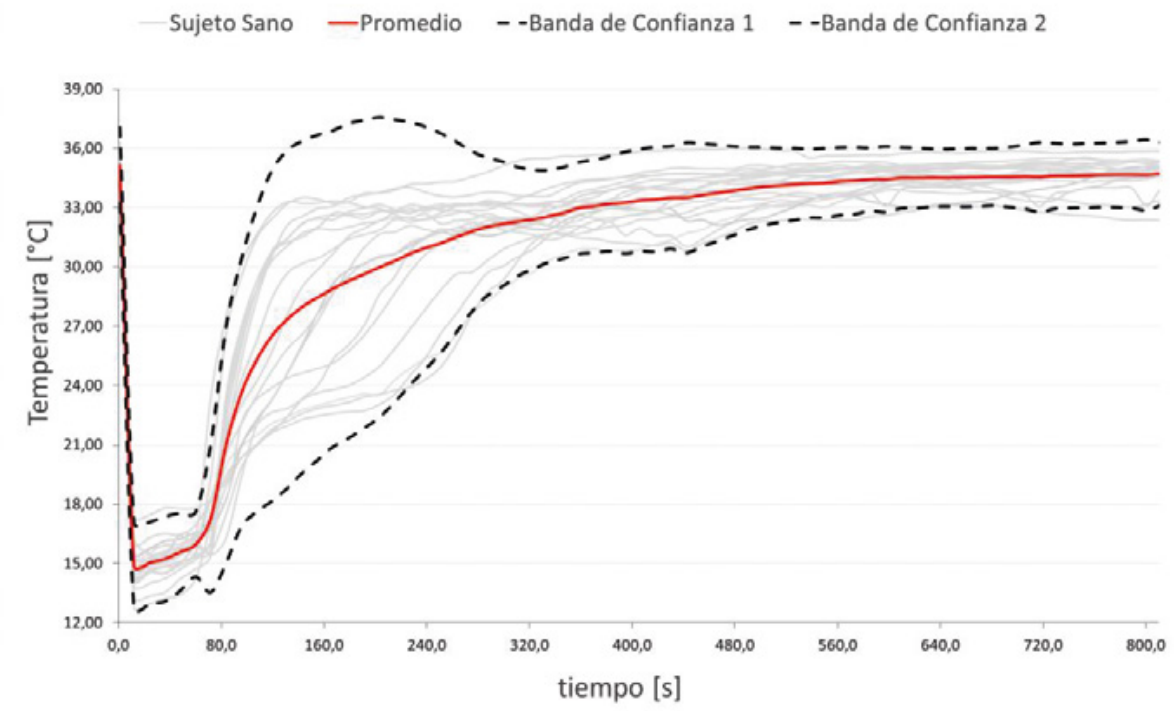

Figura 6. Curvas de temperatura en función del tiempo, correspondientes a las 18 mediciones intrasujeto (líneas grises), Curva promedio (línea roja) y bandas de confianza (líneas quebradas negras) de un único sujeto evaluado.

\section{Comparación Intrasujeto: Fatiga}

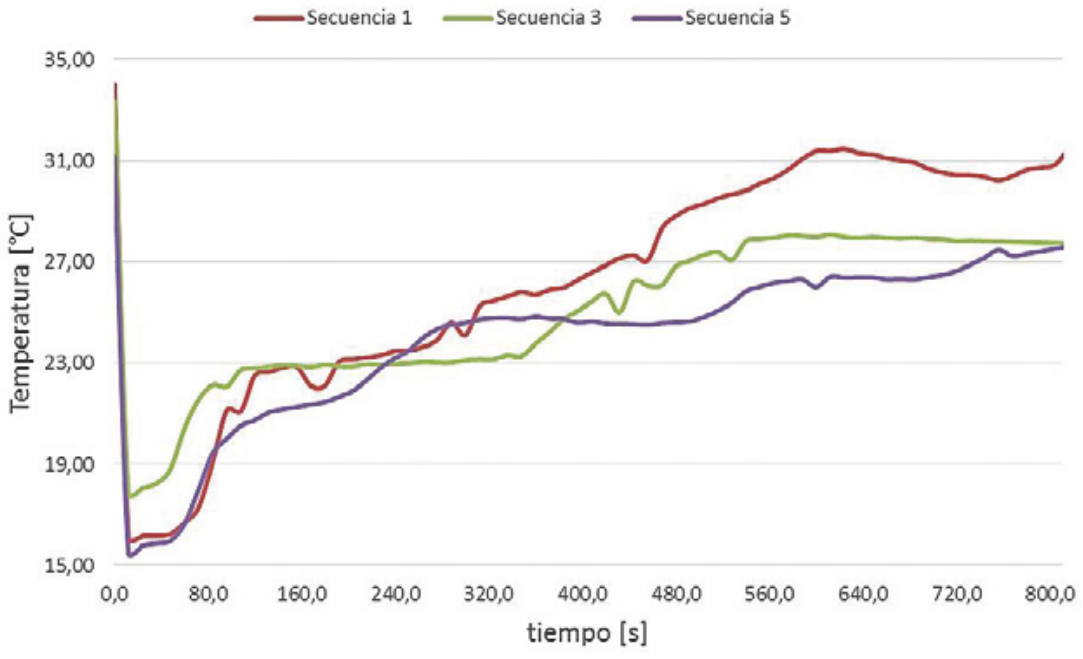

Figura 7. Curvas de temperatura en función del tiempo correspondientes a las mediciones consecutivas intrasujeto con tiempo de reposo entre las mediciones de 15 minutos. Se presentan las mediciones realizadas en el Dedo 3 (central) durante la prueba de fatiga en las secuencias de mediciones $\mathrm{N}^{\circ}$ । (rojo), $\mathrm{N}^{\circ} 3$ (verde) y N. ${ }^{\circ} 5$ (morado) de un único sujeto evaluado. 


\section{Comparación de las curvas de temperatura en relación al tiempo: mediciones intersujetos}

La variabilidad de las 16 mediciones intersujeto se presentan en la figura 8. Como se puede observar más del 95\% de las curvas se encontraron dentro de las bandas de confianza, lo que indica una baja variabilidad de los datos entre diferentes sujetos.

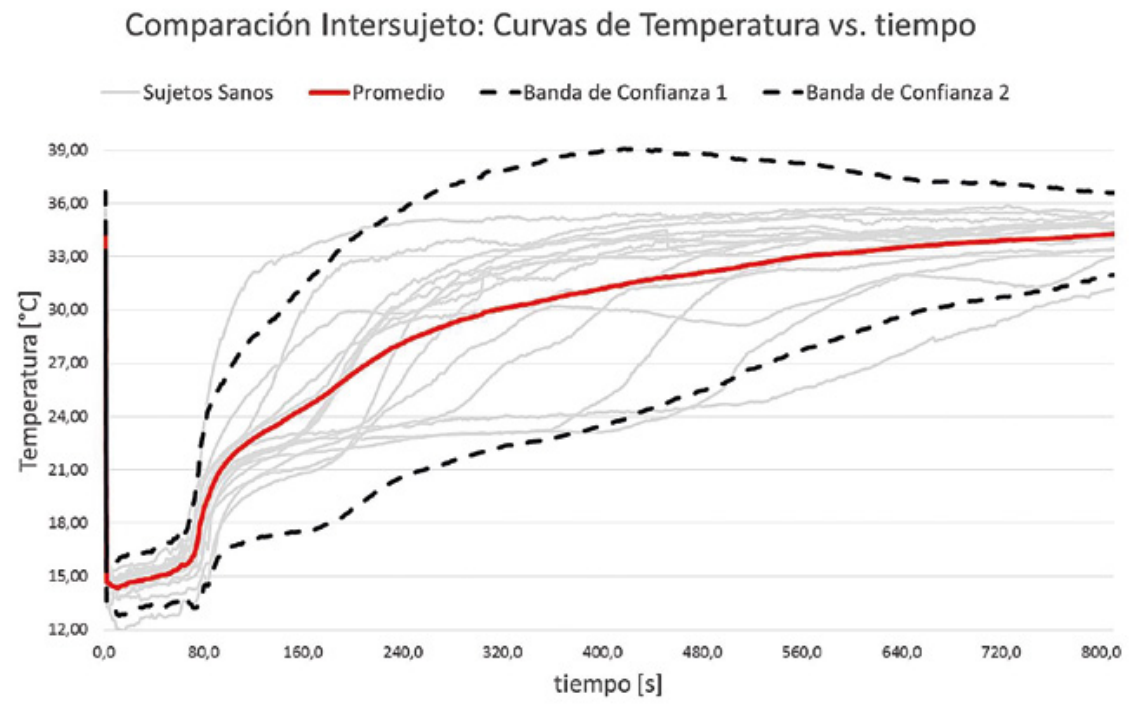

Figura 8. Curvas de temperatura en función del tiempo de las 16 mediciones intersujeto (líneas grises), curva promedio (línea roja) y bandas de confianza (líneas quebradas negras), correspondientes a los 16 sujetos sanos que reaclimataron.

\section{Discusión}

En este trabajo el soporte de acrílico permitió que el estímulo frío en la mano se realizara por inmersión en agua fría, lo cual garantizó el valor de la temperatura para el estímulo sin tener que cambiar la posición de la mano durante el proceso. Este soporte también permitió mantener la mano en posición horizontal y, con esto, controlar o suprimir la movilidad de la mano de manera que se evitaran errores introducidos por el movimiento. Lo anterior fue muy importante para optimizar el análisis de las imágenes después de su adquisición.

Estupiñán y colaboradores (2013) [2I] realizaron el estímulo frío en una caja cerrada con aire frío durante 60 segundos, pero no controlaron la temperatura del estímulo, la cual puede afectar la repetibilidad del protocolo, ya que la temperatura de estimulación es un parámetro fundamental para determinar cómo será la respuesta del sistema de termorregulación; además, la mano del paciente se posicionó vertical, sin método de fijación, lo que influyó en el resultado de las imágenes agregando un artefacto de movimiento. Este problema del artefacto fue solucionado por los autores realizando el registro de las manos antes y después del estímulo para garantizar que los datos adquiridos de las regiones de interés no se alteraran en las mediciones a diferentes tiempos. Otros estudios han presentado el mismo problema, pero no han reportado cómo lo han tratado ni tampoco los errores en los registros de temperatura debido a los movimientos del paciente $[6,8,9, \mid 4,2$ I]. 
En el presente estudio se consideró adecuado realizar una medición de la temperatura de la mano antes del estímulo para garantizar la estabilidad de la temperatura basal al comienzo de la prueba y para calcular el porcentaje de reaclimatación de la mano a intervalos de tiempo definidos después del estímulo, parámetros importantes para evaluar el sistema termorregulador, diferente a lo realizado en el trabajo de Smits y colaboradores (20l I) [ I l], en el que las imágenes de termografía infrarroja se empezaron a adquirir después del estímulo y no se obtuvieron imágenes previas. Estas y múltiples investigaciones realizadas para el análisis de la termorregulación mediante termografía infrarroja no presentan un único protocolo de adquisición, no lo reportan completo u omiten especificaciones importantes de los parámetros de adquisición aplicados [8,16,22,27], lo que hace difícil comparar los resultados entre dichos estudios y respecto al presente trabajo.

Las diferencias encontradas en este estudio entre el sujeto que no reaclimató y los demás individuos sanos fueron muy significativas, aunque el sujeto no reportó molestias ni dolor durante el estudio. En esta persona la temperatura en la punta de los dedos antes del estímulo fue de $31{ }^{\circ} \mathrm{C}$ y la temperatura de buena parte de la mano a los 10 minutos del estímulo no superó los $25^{\circ} \mathrm{C}$, especialmente en el dedo índice. Estos hallazgos son similares a los reportados previamente en estudios en pacientes con intolerancia al frío y fenómeno de Raynaud. En un caso de intolerancia al frío, evaluado por termografía infrarroja por Ruijs y colaboradores (2008) [8], las temperaturas de los dedos afectados antes del estímulo se reportaron cercanas a los $34^{\circ} \mathrm{C}, \mathrm{y}$ luego de nueve minutos del estímulo, basado en sumergir la mano en agua fría a $15^{\circ} \mathrm{C}$ durante cinco minutos, las puntas de los dedos afectados continuaban con temperaturas cercanas a la de estimulación ( $16^{\circ} \mathrm{C}$ ). Por su parte, Schlager y colaboradores (2010) [16], en 25 pacientes con fenómeno de Raynaud, utilizando termografía infrarroja, reportaron que la temperatura promedio antes del estímulo en los dedos afectados era de $31,2^{\circ} \mathrm{C}$, y luego de 20 minutos de un estímulo consistente en sumergir la mano en agua fría a $20^{\circ} \mathrm{C}$ durante un minuto la temperatura promedio de los dedos fue de $28,5^{\circ} \mathrm{C}$.

El análisis estadístico de los porcentajes de reaclimatación para comparar las mediciones intrasujeto e intersujeto en este estudio se realizó distribuyendo los datos en dos muestras y comparando si pertenecían a la misma población (sujetos sanos). Dado que los datos presentaron una distribución normal la prueba utilizada para verificar la igualdad de varianzas fue la prueba F y para verificar la igualdad de medias la prueba t-student, las cuales mostraron para todos los dedos de la mano que pertenecían a la población de sujetos sanos. Esto indicó la baja variabilidad intrasujeto e intersujeto en las mediciones termográficas y dio cuenta de la repetibilidad y reproducibilidad de la técnica diagnóstica y el protocolo de adquisición propuesto en este estudio, lo que sugiere que las variables consideradas introducían un error pequeño en las mediciones.

Schlager y colaboradores (2010) [16] en su trabajo utilizaron pruebas como la chi-cuadrado para la comparación de proporciones y la prueba $U$ de Mann-Whitney para la comparación univariada de los datos continuos obtenidos en los individuos con fenómeno de Raynaud y los controles sanos pareados. Además, aplicaron el método de Spearman para correlacionar los datos de temperatura de los dedos determinada en las imágenes de termografía infrarroja con los datos de perfusión tisular periférica determinada por láser Doppler, con la que encontraron una correlación significativa entre ambas técnicas diagnósticas, antes y después del estímulo frío, para ambos grupos de estudio, lo que demuestra la reproducibilidad del protocolo de termografía infrarroja utilizado. 
Pauling y colaboradores (20 I I) [27], para comparar las imágenes de termografía infrarroja de dos grupos patológicos, pacientes con fenómeno de Raynaud y pacientes con esclerosis sistémica, tras la aplicación de estímulo frío utilizaron la prueba t-student de muestras independientes y la prueba de chi-cuadrado, las cuales mostraron una diferencia entre los grupos, pero en el límite de significancia (valor p cercano a 0,05). En otro estudio realizado por Lim y colaboradores (20।4) [22], en el que se evaluó la utilidad de un protocolo de termografía infrarroja para el diagnóstico del fenómeno de Raynaud, se utilizó la prueba t-student para muestras independientes para evaluar las diferencias entre la temperatura de la piel, el análisis de característica operativa del receptor (curva ROC; del inglés, Receiver Operating Characteristic) para determinar el valor óptimo del punto de corte, y el coeficiente de correlación intraclase (ICC; del inglés, Intraclass Correlation Coefficients) para evaluar la reproducibilidad del estudio. Los resultados mostraron que la diferencia en la temperatura de los dedos tras el estímulo frío diferencia a los pacientes con fenómeno de Raynaud de los controles sanos y con alta reproducibilidad para los cuatro de los cinco dedos de la mano.

En aplicaciones diferentes a la termografía infrarroja algunos autores han evaluado las variaciones en las mediciones intrasujeto mediante diversos métodos. Por ejemplo, Foster y colaboradores (20 I3) para comparar la respuesta auditiva a un estímulo de $1.000 \mathrm{~Hz}$, en sujetos sanos, utilizaron la prueba de los rangos con signo de Wilcoxon [28], mientras que Abur y colaboradores (2014) para analizar la reflectancia del oído medio en sujetos sanos utilizaron la prueba de permutación [29]. Para medir la variabilidad intersujeto en otros sistemas de estudio, otros autores como Klamann y colaboradores (2012), en la investigación del uso rutinario y la aplicabilidad de un nuevo dispositivo de termografía ocular, analizaron la superficie ocular de 30 sujetos sanos utilizando el coeficiente de correlación intraclase, donde obtuvieron una alta reproducibilidad en las mediciones [30]; Henriksen y colaboradores (2012) evaluaron la variabilidad de las mediciones del flujo cerebral en sujetos sanos mediante imágenes de resonancia magnética y tomografía por emisión de positrones (PET; del inglés, Positron Emission Tomography) utilizando el modelo lineal mixto [3। ], y Doty y colaboradores (20I4) evaluaron la respuesta de la activación neuronal a estímulos de miedo mediante resonancia magnética en sujetos sanos utilizando la prueba de ANOVA, la diferencia mínima significativa de Fisher (análisis post-hoc) y prueba t con corrección de Bonferroni [32].

Los diferentes estudios donde se considera el análisis de la termorregulación utilizando termografía infrarroja no reflejan un consenso en el protocolo de adquisición utilizado y, en la mayoría de los casos, no reportan el protocolo completo o presentan omisiones en la especificación de parámetros de adquisición críticos como el campo de visión, la distancia de medición, la consideración de las condiciones ambientales, entre otros $[4,12,14,19]$. El protocolo presentado en este estudio considera las variables ambientales, la configuración del sistema de medición, el posicionamiento del sujeto y la preparación del sujeto para el estudio; siendo muy completo y con la introducción de un error pequeño en las mediciones, que es el objetivo de un protocolo. Además, especifica todas las variables consideradas, lo que permitirá que se pueda comparar en toda su extensión con otros estudios.

Desde el punto de vista fisiológico se ha mostrado que la disminución de la temperatura de la piel en las puntas de los dedos actúa como un indicador de los cambios en la microcirculación inducida por el sistema nervioso simpático. Las disminuciones de temperatura ocurren como resultado de la vasoconstricción, la cual muestra una respuesta exacerbada en sujetos afectados por condiciones patológicas como el fenómeno de Raynaud, la intolerancia al frío y el síndrome de dolor regional complejo [4,33]. Por su parte, para la ingeniería, el hecho de que sea posible 
analizar la termorregulación a partir de regiones de interés pequeñas en comparación con el área total de la superficie de la mano en las imágenes de termografía infrarroja, supone la apertura de una ventana hacia la utilización de metodologías de procesamiento digital de imágenes termográficas que contribuyan a la automatización de la selección de las regiones de interés, lo que hace posible el análisis de la termorregulación en ambientes no colaborativos, por ejemplo, cuando no es posible evitar pequeños movimientos de la mano en la secuencia de imágenes. Al respecto, existen metodologías de registro [34] que permiten hacer la correspondencia entre los píxeles del área de la mano en dos imágenes de termografía infrarroja, mostrando pequeños cambios en la ubicación espacial de la mano en las imágenes [13]. Esto último redundaría en el desarrollo de metodologías automatizadas y en tiempo real para el análisis de la termorregulación.

\section{Conclusiones}

El protocolo de adquisición de imágenes de termografía infrarroja que se diseñó y se presentó en este trabajo brinda una herramienta de soporte útil para el diagnóstico del proceso de termorregulación de la mano, que permite minimizar la variabilidad de las mediciones obtenidas a partir de las imágenes termográficas y así disminuir la probabilidad de errores en un potencial diagnóstico posterior. Estas características son particularmente importantes teniendo en cuenta que variables externas como las condiciones ambientales, la configuración del sistema de medición, la preparación del paciente para el estudio y su posicionamiento en el sistema de medición pueden afectar el resultado.

Los resultados de las pruebas de fatiga permitieron concluir que es necesario tener en cuenta el tiempo de espera para repetir la prueba, especialmente en los pacientes no colaborativos y que presentan movimientos y cambios de posición de la mano durante el estudio o en los pacientes que no toleren el estímulo, ya que una vez recibido el estímulo se altera la respuesta del sistema termorregulador por un tiempo. Un resultado notable es que tras el seguimiento del protocolo de estímulo frío aplicado resulta claro que las tendencias observadas en la termorregulación de la mano se preservan, incluso en regiones proporcionalmente pequeñas de la mano como las puntas de los dedos.

El protocolo de adquisición de imágenes diagnósticas por termografía infrarroja presentado en este trabajo ha sido validado y puede ser reproducido para evaluar el proceso de termorregulación en condiciones patológicas como el fenómeno de Raynaud y la intolerancia al frío.

\section{Agradecimientos}

Agradecemos a Carlos Javier Barrera, Estadístico, y a Daniel Alberto Romero, Ingeniero Biomédico, del Instituto Tecnológico Metropolitano de Medellín (ITM) por sus valiosos aportes a este trabajo y a la institución por permitirnos disponer de los laboratorios y tecnología necesaria para llevar a cabo este trabajo.

\section{Bibliografía}

I. Maldague XPV. Nondestructive Evaluation of Materials by Infrared Thermography (ed Ira). Londrés, Reino Unido: Springer-Verlag London; 1993.
2. Carlomagno GM, Cardone G. Infrared thermography for convective heat transfer measurements. Exp Fluids 20 I0; 49: 1 187-1218. 
3. Fernández-Cuevas I, Bouzas Marins JC, Arnáiz Lastras J, Gómez Carmona PM, Piñonosa Cano S, García-Concepción MÁ, et al. Classification of factors influencing the use of infrared thermography in humans: A review. Infrared Phys Techn 2015; Mar 9 [Epub ahead of print].

4. Niehof SP, Huygen FJ, van der Weerd RW, Westra M, Zijlstra FJ. Thermography imaging during static and controlled thermoregulation in complex regional pain syndrome type I: diagnostic value and involvement of the central sympathetic system. Biomed Eng Online 2006; 5: 30.

5. Knobel RB, Guenther BD, Rice HE. Thermoregulation and thermography in neonatal physiology and disease. Biol Res Nurs 201 I; 13: 274-282.

6. Hildebrandt C, Raschner C, Ammer K. An overview of recent application of medical infrared thermography in sports medicine in Austria. Sensors (Basel) 2010; 10: 4700-47|5.

7. Ring EF, Ammer K. Infrared thermal imaging in medicine. Physiol Meas 2012; 33: R33-46.

8. Ruijs AC, Jaquet JB, Brandsma M, Daanen HA, Hovius SE. Application of infrared thermography for the analysis of rewarming in patients with cold intolerance. Scand J Plast Reconstr Surg Hand Surg 2008; 42: 206-2I 0.

9. Nancarrow JD, Rai SA, Sterne GD, Thomas AK. The natural history of cold intolerance of the hand. Injury 1996; 27: 607-611.

10. Schuhfried O, Vacariu G, Lang T, Korpan M, Kiener HP, Fialka-Moser V. Thermographic parameters in the diagnosis of secondary Raynaud's phenomenon. Arch Phys Med Rehabil 2000; 81: 495-499.

II. Smits ES, Nijhuis TH, Huygen FJ, Selles RW, Hovius SE, Niehof SP. Rewarming patterns in hand fracture patients with and without cold intolerance. J Hand Surg Am 20II; 36: 670-676.

12. Fleta Zaragozano J, Rodríguez Martínez G, Olivares López JL. Fenómeno de Raynaud. Acta Pediatr Esp 2009; 67: 297-300

13. Nijhuis TH, Smits ES, Jaquet JB, Van Oosterom FJ, Selles RW, Hovius SE. Prevalence and severity of cold intolerance in patients after hand fracture. J Hand Surg Eur Vol 2010; 35: 306-3II.

14. Craigen M, Kleinert JM, Crain GM, McCabe SJ. Patient and injury characteristics in the development of cold sensitivity of the hand: a prospective cohort study. J Hand Surg Am 1999; 24: 8-15.

15. Bakst R, Merola JF, Franks AG, Jr., Sanchez M. Raynaud's phenomenon: pathogenesis and management. J Am Acad Dermatol 2008; 59: 633-653.

16. Schlager O, Gschwandtner ME, Herberg K, Frohner $\mathrm{T}$, Schillinger M, Koppensteiner R, et al. Correlation of infrared thermography and skin perfusion in Raynaud patients and in healthy controls. Microvasc Res 2010; 80: 54-57.

17. Bouzida N, Bendada AH, Piau JM, Akhloufi M, Maldague $X$, Raymond M. Using lock-in infrared thermography for the visualization of the hand vascular tree In: Vavilov VP, Burleigh DD eds. Thermosense XXX. Vol. 6939: Proc. of SPIE; 2008.

18. Bouzida N, Bendada A, Maldague XP. Observation of the human body thermoregulation and extraction of its vein signature using NIR and MWIR imaging. In: Cullum
BM, Porterfield DM eds. Smart Biomedical and Physiological Sensor Technology VI. Vol. 73I 3: Proc. of SPIE; 2009.

19. Taylor NAS, Tipton MJ, Kenny GP. Considerations for the measurement of core, skin and mean body temperatures. J Therm Biol 2014; 46: 72- I0 I.

20. Zaproudina N, Varmavuo V, Airaksinen O, Narhi M. Reproducibility of infrared thermography measurements in healthy individuals. Physiol Meas 2008; 29: 5I 5-524.

21. Estupinan Roldan K, Piedrahita MAO, Dario Benitez H. Design and implementation of a protocol for acquisition and processing of infrared images obtained from hands. Image, Signal Processing, and Artificial Vision (STSIVA), 2013 XVIII Symposium of; 20। 3: I-7.

22. Lim MJ, Kwon SR, Jung KH, Joo K, Park SG, Park W. Digital thermography of the fingers and toes in Raynaud's phenomenon. J Korean Med Sci 20 I4; 29: 502-506.

23. Matsuura Y, Naito K. Flexible hollow optical fiber bundle for infrared thermal imaging. Biomed Opt Express 2010 2: 65-70.

24. Høiland II, de Weerd L, Mercer JB. The effect of oral uptake of nicotine in snus on peripheral skin blood circulation evaluated by thermography. Temperature 20 I4; I: 220-226.

25. Verdoux H, Takei N, Cassou de Saint-Mathurin R, Bourgeois M. Analysis of the seasonal variation of schizophrenic births using a Kolmogorov-Smimov type statistic. Eur Psychiatry 1997; 12: I | I- 116.

26. Moncada Jiménez J. Estadística para las ciencias del movimiento humano (ed Ira). San José , Costa Rica: Editorial de la Universidad de Costa Rica; 2005.

27. Pauling JD, Flower V, Shipley JA, Harris ND, McHugh $\mathrm{NJ}$. Influence of the cold challenge on the discriminatory capacity of the digital distal-dorsal difference in the thermographic assessment of Raynaud's phenomenon. Microvasc Res 201 I; 82: 364-368.

28. Foster M, Stevens J, Brennan S. Intra and intersubject variability in auditory steady-state response amplitude with high modulation rates to $1000 \mathrm{~Hz}$ amplitude modulated and tone pip stimuli. Int J Audiol 20 I3; 52: 507-5 I2.

29. Abur D, Horton NJ, Voss SE. Intrasubject variability in power reflectance. J Am Acad Audiol 20 I4; 25: 44I-448.

30. Klamann MK, Maier AK, Gonnermann J, Klein JP, Pleyer $U$. Measurement of dynamic ocular surface temperature in healthy subjects using a new thermography device. Curr Eye Res 2012; 37: 678-683.

31. Henriksen OM, Larsson HB, Hansen AE, Gruner JM, Law I, Rostrup E. Estimation of intersubject variability of cerebral blood flow measurements using MRI and positron emission tomography. J Magn Reson Imaging 2012; 35: 1290-1299.

32. Doty TJ, Japee S, Ingvar M, Ungerleider LG. Intersubject variability in fearful face processing: the link between behavior and neural activation. Cogn Affect Behav Neurosci 2014; | 4: |438-| 453.

33. Kistler A, Mariauzouls C, von Berlepsch K. Fingertip temperature as an indicator for sympathetic responses. Int J Psychophysiol 1998; 29: 35-41.

34. Holden M. A Review of Geometric Transformations for Nonrigid Body Registration. Medical Imaging, IEEE Transactions on 2008; 27: I I I- 128. 